\title{
A presença do autor em Finisterra, de Carlos de Oliveira ${ }^{1}$
}

\author{
The authorial presence in Finisterra, by Carlos de Oliveira
}

\author{
Giseli Seeger ${ }^{2}$ \\ Universidade Federal de Santa Maria, RS, Brasil.
}

\begin{abstract}
Resumo: movimentos como o formalismo russo, o new criticism e o estruturalismo francês defendiam que critérios como autor e intenção deveriam ser varridos do horizonte crítico para instaurar-se a condição de objetividade necessária ao estudo científico das obras literárias. Entretanto, em última instância, nossa experiência de leitores continua a nos dizer que tais critérios desempenham papel importante na construção do significado das obras. Nessa breve leitura de Finisterra, de Carlos de Oliveira, narrativa complexa, que à primeira vista enfraquece os sinais de autoria, propomos uma "via intermediária" para a abordagem da categoria autor. Quer dizer, evitamos, por um lado, o que W.K. Wimsatt (1946) chama a falácia intencional, "que sustenta a intenção do autor como critério para qualquer interpretação válida do texto", e, por outro, o que Paul Ricoeur designa por "falácia do texto absoluto", isto é, "o tratamento do texto como uma entidade sem autor" (RICOEUR, 1976, p. 42).
\end{abstract}

Palavras-chave: Autor. Finisterra. Carlos de Oliveira.

\begin{abstract}
: movements such as russian formalism, new criticism and french structuralism argued that criteria such as author and intention should be abolished from the critic horizon to establish the condition of objectivity necessary for the scientific study of literary works. However, ultimately, our experience of readers continues to tell us that such criteria play an important role in building the meaning of works. In this brief analysis of Finisterra, by Carlos de Oliveira, a complex narrative, which at first sight weakens the signs of authorship, we propose a "intermediary way" for the author category approach, avoiding, on the one hand, what W.K. Wimsatt (1946) calls intentional fallacy, "which sustains the author's intention as a criterion for any valid interpretation of the text", and, on the other hand, what Paul Ricoeur calls "fallacy of the absolute text", that is, "the treatment of the text as an entity without author" (RICOEUR, 1976, p. 42). Keywords: Author. Finisterra. Carlos de Oliveira.
\end{abstract}

\section{Introdução}

Finisterra. Paisagem e Povoamento é um dos episódios mais marcantes da renovação experimentada pelo romance português nas décadas de 1960 e 1970. De inserção histórico-literária bastante diversa do restante da obra de Carlos de Oliveira, esse romance encerra uma trajetória marcada pelo aprimoramento formal e pelo questionamento das bases epistemológicas em que assentara o início da carreira do escritor. Mais do que aquilo que se conta, em Finisterra é o modo de contar que assume relevância fundamental - o que se conta é, simplesmente, a história de uma família médio-burguesa em vias de desmantelar-se financeira e afetivamente. Enquanto a propriedade familiar caminha rumo à derrocada, mãe, pai e menino tentam reproduzir a paisagem exterior por mecanismos diversos - desenho, pirogravura, fotografia. No entanto, suas representações não produzem senão versões da paisagem, versões sempre distorcidas, que levam inscritas em si as sensações, os afetos, a imaginação dos artífices.

E a própria situação da narração traz consigo a marca da parcialidade: assente em uma recordação, o relato é contado, na sua maior extensão, por um 
homem que deambula pela casa da infância; seu percurso físico é também um percurso pela memória. Aquilo de que se lembra são imagens embotadas, fragmentos de sons, antigas sensações, tudo filtrado por uma visão infantil do mundo sempre contaminada pelas impressões presentes. Tanto a distância temporal quanto a febre, o sono e as fantasias da criança de outrora influem diretamente sobre a matéria rememorada. No nível do discurso, tudo se passa como se a mesma obsessão representativa dos membros da família se materializasse em extensas descrições, nas quais predomina a descrição e uma constante alusão à necessidade de "analisar", "registrar", "calcular", "medir" o mundo representado.

Além disso, não há nesse romance um narrador a tecer comentários de ordem explicativa ou moralizante em torno da ação. A problematização em torno da possibilidade de reproduzir objetivamente o mundo fica inteiramente a cargo das personagens, e as diretrizes ideológicas com as quais a obra se compromete, muito mais do que nos primeiros romances de Carlos de Oliveira, permanecem no nível da "sugestão". Tudo se passa como se o romance assumisse sub-repticiamente que, sendo relativas as perspectivas particulares, "as significações do mundo, à nossa volta, são apenas parciais, provisórias, contraditórias mesmo, e sempre contestáveis" (ROBBE-GRILLET, 1969, p. 94).

Esse pressuposto, porém, não elimina a problemática ideológica da obra. Como afirma Maria Alzira Seixo, essa "terra", ou, antes, todo o espaço romanesco de Finisterra, "tem uma função física e ética", como se a "mensagem" comunicada pela obra fosse a de que "a inalterabilidade dos processos de desenvolvimento conduz à perda e à destruição; a tentativa de deter o curso da história conduz à revolta dos oprimidos e ao esmagamento dos opressores" (1986, p. 74). Quer dizer, com essa assunção implícita, é como se a narrativa ainda tivesse "alguma coisa a dizer" (ROBBE-GRILLET, 1969, p. 95) sobre o mundo. Mas como nos chega, a nós, leitores, isso a que chamamos genericamente a "mensagem" da obra? E a quem, afinal, devemos sua formulação? Sob a chave de leitura da "presença do autor", entendida como manifestação de um conjunto de vetores axiológicos e epistemológicos na obra, propomos aqui uma hipótese a essas questões.

\section{O autor na tradição crítica}

Uma das obras mais paradigmáticas em torno da categoria autor é The rhetoric of fiction (1961), de Wayne C. Booth. Nela, Booth dispensa especial atenção ao modo como valores morais são comunicados pelas obras de ficção, concebendo-as como mundos eticamente normativos; está interessado, como aponta o título da obra, em desenvolver uma retórica do texto ficcional, dedicada principalmente aos meios narrativos usados para transmitir um sistema de valores ao destinatário. O argumento central de Booth é o de que, porquanto as estratégias empregadas em toda obra de ficção decorrem das normas e das escolhas técnicas do autor, expurgá-lo do domínio ficcional é um empreendimento condenado de partida ao insucesso. Podendo valer-se de recursos que disfarcem sua presença, o autor jamais pode desaparecer da obra; esteja ou não representado, permanece sempre como autor implicado ${ }^{3}$ (BOOTH, 1980, p. 36). Booth entende que a noção de autor implicado "inclui não só os significados que podem ser extraídos, como também o conteúdo emocional ou moral de cada parcela de acção e sofrimento de todos os personagens"; dito doutro modo, a noção inclui a "percepção intuitiva de um todo artístico completo; o principal valor com o qual este autor implícito se comprometeu, independentemente do partido a que pertence na vida real - isto é, o que a forma total exprime" (BOOTH, 1980, p. 91, grifo do autor). Segundo ele, entretanto,

\footnotetext{
3 A tradução utilizada emprega "autor implícito". Quanto a nós, entendemos que tradução mais acertada para o conceito proposto por Booth é "autor implicado", uma vez que seu foco são as estratégias discursivas que dão a ver a presença do autor; i.e., a ênfase do conceito está muito mais na incontornabilidade da explicitação de valores e posições axiológicas através do funcionamento discursivo do que no caráter relativamente encoberto (implícito, não diretamente materializado) da entidade autor.
} 
a partir de Flaubert, foram muitos os autores e críticos que se convenceram de que os modos de narração ‘objectivos', 'impessoais' ou ‘dramáticos' são naturalmente superiores a qualquer modo que dê lugar ao aparecimento directo do autor ou do seu porta-voz fidedigno (BOOTH, 1980, p. 26).

Booth refere-se à alternativa oferecida por grande parte da ficção moderna de substituir o tradicional narrador "onisciente" por consciências sujeitas a limitações de conhecimento, substituição que fortalece a impressão de que a história, autossuficiente, conta-se a si mesma. Ao privilegiarem não o contar (telling), mas o mostrar (showing), eliminando de suas ficções os comentários e juízos explícitos, romancistas como James e Hemingway - diferentemente de um Fielding ou de um Dickens - dificultam o desvendamento dos juízos do autor. Nesse caso, porém, tais juízos ainda podem ser deduzidos dos próprios mecanismos discursivos: dos deslocamentos de ponto de vista, de alusões literárias, da escolha de imagens, do recurso a determinados mitos e símbolos, de resumos, cortes e condensações temporais, da organização e disposição dos episódios etc. "Um leitor esclarecido", defende Booth, "aperceber-se-á de que todos eles [todos esses mecanismos] são impostos pelo autor" (BOOTH, 1980, p. 36).

Importante sublinhar que, para Booth, o autor implicado não se confunde com o narrador, pois, como as personagens, o espaço ou o tempo, essa figura não é senão um dos elementos estruturantes criados pelo autor implicado. O narrador não passa, afinal, "de mais um dos elementos criados pelo autor implícito e pode dele ser diferenciado por amplas ironias" (BOOTH, 1980, p. 90). Se o narrador "é geralmente aceite como o 'eu' da obra, esse 'eu' raramente, ou mesmo nunca, é idêntico à imagem implícita do artista" (BOOTH, 1980, p. 90). O autor implicado de Booth não se confunde tampouco com o autor empírico. Para ele, até mesmo o romance que não tem um narrador dramatizado cria a imagem de um "autor nos bastidores", que é sempre distinto de um "homem a sério", criação sua tanto quanto o é a própria obra (BOOTH, 1980, p. 167).

Pode-se, evidentemente, criticar a proposta de Booth, como fazem Tom Kindt e Hans Harald Müller (2006) ${ }^{4}$ em trabalho dedicado a levantar desdobramentos teóricos e controvérsias ligados ao conceito de autor implicado. De acordo com Kindt e Müller, há uma ambiguidade fundamental da tese de Booth: por um lado, ele assume que, quando escrevem seus textos, os autores sempre criam imagens de si mesmos no processo: segundo ele, "enquanto escreve, o autor não cria, simplesmente, um 'homem em geral', impessoal, ideal, mas sim uma versão implícita de 'si próprio', que é diferente dos autores implícitos que encontramos nas obras de outros homens" (BOOTH, 1980, p. 88). Por outro lado, ele descreve o autor implicado como uma inferência feita por receptores reais: "por impessoal que ele tente ser, o leitor construirá, inevitavelmente, uma imagem do escriba oficial que escreve dessa maneira" (BOOTH, 1980, p. 89). De acordo com essa segunda definição, o autor empírico não deve ser visto como o criador do implicado; ele simplesmente fornece, intencionalmente ou não, o material do qual o último é construído. A partir dessa perspectiva, o autor implicado é a imagem que os leitores fazem do escritor de um texto ao ler o texto.

No entender de Kindt e Müller, a disseminação da tese de Booth se deve justamente às incoerências que a caracterizaram. Ao longo dos anos, o autor implicado foi tomado ora como fenômeno da recepção, ora como participante da comunicação, ora como sujeito postulado por detrás do texto. Desde os anos 1970, o conceito encontrou reformulação, para citar apenas os exemplos mais proeminentes, no "autor modelo" de Umberto Eco, no "autor abstrato" de Wolf Schmid e no "leitor implicado" de Wolfgang Iser. E alternativas não deixam de surgir, muitas delas derivadas de discussões recentes em torno da relevância narratológica da categoria autor.

Gérard Genette, fundador da narratologia estrutural, chamada "clássica", em Le nouveau discours du

4 Kindt e Müller são ambos pesquisadores de literatura alemã moderna na Universidade de Hamburgo. O texto mencionado é The implied author. Concept and controversy (2006). 
récit (1983), nega a necessidade de contemplar a figura do autor implicado no estudo do discurso narrativo. Em seu juízo, o autor implicado não é senão uma complicação desnecessária da enunciação narrativa: "Na minha opinião, a narratologia não precisa ir além da instância narrativa, e as instâncias de autor e leitor implícitos estão claramente além de tal instância. Essa questão não é, para mim, responsabilidade da narratologia" (GENETTE, 1983, p. 94; tradução nossa) 5 .

Porém, de acordo com José Angel García Landa $(1998)^{6}$, essa é uma interpretação demasiado estreita do campo da narratologia, que deve atender não somente à forma tangível do relato como também a toda a sua estrutura, incluindo nela todos os fatores virtuais que intervêm na comunicação narrativa. Para Landa, narrador e autor textual [ou implicado] se definem reciprocamente, por oposição um ao outro ou por identidade, e por isso não podemos deixar um dentro e outro fora do esquema descritivo. Como grande parte dos teóricos dos atuais estudos narrativos, Landa defende uma concepção da narratologia muito mais ampla que a de Genette - uma narratologia que englobe o estudo teórico do que é propriamente narrativo em todos os seus aspectos (LANDA, 1998, p. 402). De sua parte, Fotis Jannidis $(2005)^{7}$ reconhece que, embora a maior parte das teorias da comunicação narrativa sublinhe a diferença essencial entre autor, narrador e autor implicado, muitas vezes a ponto de excluir o autor da análise narratológica, a maioria dos leitores continua a usar o texto como base para processos inferenciais que constroem uma imagem do autor. Essa imagem é construída não apenas com base em pistas internas ao texto, mas também com base no conhecimento derivado de paratextos e outras fontes mobilizadas durante o ato da leitura (JANNIDIS, 2005, p. 85).
Algumas das atuais discussões no campo, como a empreendida por Kindt e Müller, giram em torno da própria noção de intencionalidade. Se a proposta de Wayne C. Booth se pretende corolário da retórica anti-intencionalista advogada pelos formalistas russos, pelo New Criticism e pelo estruturalismo francês, decorrendo suas principais ambiguidades da tentativa de conciliar a descrição puramente textual com a concepção das narrativas como mundos eticamente constituídos, Kindt e Müller consideram a intenção um critério válido para uma correta interpretação da obra. Por intenção compreendem eles não as experiências, as associações, os pensamentos e sentimentos que os autores tinham em mente ao produzirem suas obras, mas as ideias que os escritores procuravam expressar em textos moldados para ter certa forma (KINDT; MULLER, 2006, p. 169, grifo nosso).

Os teóricos defendem que elucidar a noção de autor implicado no contexto do intencionalismo hipotético nos permite levar em conta a ideia de Booth de que o autor implicado deve ser identificado com base em "todas as escolhas que o autor fez de fato, consciente ou inconscientemente" (KINDT; MÜLLER, 2006, p. 175), quer dizer, de acordo com as ideias e convenções mobilizadas na feitura da obra e recuperadas pelo leitor. Para eles, uma reconstrução do autor implicado, ou antes, do que preferem chamar "autor hipotético" ou "postulado", em consonância com a proposta de William E. Tolhurst (1979) ${ }^{8}$, pode, pois, ser introduzida pela descrição das estruturas textuais, o que não significa que dela decorra direta e unicamente, como pretendera a tradição crítica anterior (KINDT; MÜLLER, 2006, p. 159).

Quanto a nós, entendemos que a proposta de Booth, a despeito de suas ambiguidades, continua a ser um instrumental eficaz para pensar a categoria autor, na medida em que seus pressupostos básicos

\footnotetext{
5 Do original, À mon sens, la narratologie n'a pas à aller au-delà de l'instance narrative, et les instances de l'implied author et de l'implied reader se situent clairement dans cet au-delà. Mais si cette question n'est pas pour moi du ressort de la narratologie (GENETTE, 1983, p. 94) 6 Landa é pesquisador espanhol, especialista em teoria literária e narratologia. Aludimos ao capítulo "Perspectiva", do livro Acción, relato, discurso. Estructura de la ficción narrativa (1998).

7 Jannidis está entre os nomes mais proeminentes dos atuais estudos narrativos. Referimo-nos ao -seu verbete em torno da categoria autor na Routledge Encyclopedia of Narrative Theory (2005), organizada por David Herman, Manfred Jahn e Marie-Laure Ryan.

8 Cf. TOLHURST, William E. On What a Text Is and How It Means. The British Journal of Aesthetics, v. 19, n. 1, p. 3-14, jan. 1979.
} 
sobrevivem às diferentes críticas de que fora alvo o conceito de autor implicado - as obras de ficção, como mundos eticamente construídos, comunicam valores morais; algumas delas, sobretudo as alinhadas à tradição modernista e pós-modernista, promovem o "acrescimento e [a] multiplicação das significações possíveis de uma mensagem" (ECO, 2015, p. 125), relegando esses valores ao nível da sugestão. É isso o que faz Finisterra, cujas diretrizes ideológicas, alinhadas ao neo-realismo português, mais especificamente, aos pressupostos do materialismo histórico-dialético que atravessam a obra de Carlos de Oliveira, dependem, para serem compreendidas, de um esforço de dedução por parte do leitor, convidado constantemente a desafiar a complexa tessitura dum discurso narrativo de feição post-modernista.

Como Kindt e Müller, porém, advogamos uma espécie de "via intermediária", alternativa teórica entre duas posições radicais: o intencionalismo compreendido em termos psicologizantes e biografistas, e o formalismo/estruturalismo estritos, ou a tomada da obra como entidade destituída de autor. A adoção dessa via nos permite convocar para a análise de Finisterra o conteúdo semântico e ideológico do texto sem recair em análise restrita aos mecanismos discursivos. Concebendo a categoria autor como uma noção semântica postulada pelo leitor durante o ato da leitura, nossa aproximação, por breve, pretende desvendar algumas estratégias discursivas que traem no romance a presença do autor, convocando ideias que, sugeridas sem serem dadas diretamente pelo texto, participam da construção de seu significado.

\section{A presença do autor em Finisterra}

A ação de Finisterra centra-se em dois núcleos de personagens, a que chamaremos "núcleo doméstico" e "núcleo peregrino". O núcleo doméstico, composto pelas personagens do pai, da mãe, da mulher, da criança/homem, do tio e do amigo da família, circunscreve-se fundamentalmente ao espaço da casa. O núcleo peregrino é constituído por camponeses que, no exterior, atravessam a paisagem em fuga do calor excessivo e de uma tempestade de relâmpagos de carbureto; junto deles, seguem bois, cavalos e carneiros que lhe garantem a subsistência e que, por uma espécie de corte fantástico, também dão sua parte da história. No intermédio dos dois grupos, no que chamaremos núcleo intermediário, há um executor fiscal, que alerta a família de sua falência insolúvel, e um técnico de hipotecas, que decreta o fundamento ilegal da propriedade. Essas personagens transitam entre interior e exterior, isto é, entre a paisagem atravessada pelos peregrinos e a casa da família.

Para além das figuras do executor e do técnico de hipotecas, que vêm exercer a força da lei, os fenômenos naturais do exterior também ameaçam a casa: as raízes da gisandra, planta carnívora que em princípio só germina nos solos da ficção, espraiam-se pelas dunas e corroem os alicerces; uma tempestade de relâmpagos e o excesso de névoa fazem oscilar o halo luminoso que circunda as paredes externas. No interior da casa, são as tensões afetivas a minarem a estrutura familiar. O pai, entregue à modorra e como que indiferente a tudo, bebe sucessivas doses de brandy; o tio, filho mais velho, que prometera ao velho pai conservar a propriedade, idealiza a construção de uma fábrica de porcelana que venha afastar a ruína: "[f]ica por minha conta: hei de decifrá-lo [o enigma da porcelana, supostamente presente num epítome do espólio familiar] a tempo de salvar a casa" (OLIVEIRA, 2003, p. 38); mas o pai, ou antes, a voz lenta, os ombros a encolherem-se, mostra-se sempre impassível: "[e] quando descobrires a fórmula, falamos" (OLIVEIRA, 2003, p. 38); o amigo da família também não crê ser possível a descoberta: “[n]ão vejo onde possa esconder-se a fórmula da porcelana. Nem admira: de textos esotéricos, entendo pouco; não entendo nada (para ser sincero)" (OLIVEIRA, 2003, p. 38). O amigo da família, de sua parte, empenha-se em subornar o executor fiscal; pretende ao menos "a rasura na data duma hipoteca; o algarismo trocado, os prazos subvertidos" (OLIVEIRA, 2003, p. 94).

O núcleo peregrino, diferentemente, é destituído de tensões internas. Todos os seus conflitos decorrem da exploração a que os proprietários os submetem. Por um aproveitamento particular da- 
quele dispositivo de ficcionalização a que Genette ${ }^{9}$ chamou "metalepse", os camponeses e os animais derivam do próprio desenho da criança. Essas personagens coletivas dão-nos a conhecer, antes de mais, uma oposição entre exploradores e explorados. Ao imiscuírem-se na narração, projetados nas paredes da casa pelo animatógrafo do pai, os peregrinos e os animais comunicam sua perspectiva e propõem a iminência da inversão dessa hierarquia:

\begin{abstract}
Na projeção imóvel, camponeses, cavalos, bois, carneiros, começam a falar. [...] Falem os cavalos. Sofrer o ferro em brasa, as siglas tatuadas a lume. Forma de sadismo rural [...]. Cheiro a carne queimada, ferimentos perto da gangrena, cicatrizes que o frio acorda de vez em quando: nunca mais se esqueçam. [...] Queixam-se [os cavalos], maldizem o desenho [...].

Só falaram do fogo (foste avisado desde o início). E fogo não falta no desenho. Altera as proporções, excita, queima, gera desavenças. Abusaste. (OLIVEIRA, 2003, p. 31-34).
\end{abstract}

Representante de uma burguesia rural, o núcleo doméstico encontra-se em vias de perder a propriedade e, com ela, o poder de dominação que há gerações exerce sobre o núcleo peregrino, que, se sofrera duras penas, sujeito à consciência criadora da criança, há de romper com a própria condição de explorado: "[q]ualquer dia a canga (a paciência) acaba. Esperança vai havendo" (OLIVEIRA, 2003, p. 34 ), dizem os bois ao aproximar-se a lupa do adulto. Inversamente, com o recurso à metalepse, as personagens do núcleo doméstico veem rompidas tanto a sua dominância enunciativa quanto sua soberania política, subordinados eles próprios à Banca que vem executar a hipoteca da casa. Isto é, enquanto a figuração do núcleo peregrino é investida de uma propensão emancipatória, confirmada pela perspectivação (algo utópica) do futuro, a do núcleo peregrino é toda ela assente no passado: não só porque o próprio motor do relato é a memória do adulto que deambula por uma casa arruinada, mas também porque toda a história contada repousa em uma tentativa (vã) de frear o devir histórico-social. Materialmente, a casa é ameaçada pela névoa e pela gisandra, elementos naturais que corroem os tetos e dissolvem os alicerces; financeiramente, pela irreversibilidade da hipoteca; afetivamente, pelos conflitos que minam as relações intrafamiliares e pela suposta esterilidade da mulher, que impede a manutenção do elo hereditário ("dirigindo-se ao homem, a criança indaga: 'os filhos [dos peregrinos] também fugiram das aldeias queimadas. Mas hão de crescer, multiplicar-se. E os teus?'”) (OLIVEIRA, 2003, p. 56). ${ }^{10}$

O núcleo peregrino, apesar de secundário na economia da narrativa, ganha, pois, importância axiológica ao ser marcado pelo interesse coletivo, por uma postura altiva e pela esperança, enquanto o núcleo doméstico, embora protagonista, perde em valorização moral por enfraquecido, corrompido e ameaçado. Ao estabelecer essa diferença, o texto direciona a simpatia do leitor para o núcleo peregrino, sugerindo, pelas próprias estratégias discursivas, um ponto de vista solidário do autor para com a classe social que tal núcleo representa.

A presença do autor se revela ainda no discurso das personagens comprometidas com a representação da paisagem externa. Ao refletir sobre o ato que empreendem, as figuras encarnam um dilema conceitual que corresponde ao do próprio artista na feitura da obra. Ao lavrar a fogo na almofada a paisagem vista da janela, a mãe sugere o próprio funcionamento da perspectiva no romance. Afirma não esperar que sua imaginação "se desprenda" da paisagem: "[n]as relações sujeito-objecto, o sujeito faz parte da realidade e sem ele (que sente as coisas) nada teria sentido" (OLIVEIRA, 2003, p. 27); para a personagem, teria sido a sua "imaginação (partindo do real, eu sei)" a construir a gravura abstrata, como em uma espécie

\footnotetext{
9 GENETTE, Gérard. Discurso da narrativa. Lisboa: Vega, 1976.

${ }_{10}$ As mesmas oposições (futuro/passado; fertilidade/esterilidade; esperança/desesperança;/conflitos internos/ausência de conflitos internos) se verifica em Uma abelha na chuva, entre os casais Álvaro Silvestre e Maria dos Prazeres e Jacinto e Clara, recorrências que assinalam as obsessões temáticas e ideológicas do autor.
} 
de "magia para filtrar o mundo, dar-lhe algum sentido" (OLIVEIRA, 2003, p. 28, grifo nosso). Já o homem, ao construir a maquete, pretende uma correspondência entre o real e a sua representação; para ele, "[o] modelo copia o real, sem deturpar" (OLIVEIRA, 2003, p. 58). Em uma posição intermediária entre as duas concepções da mimesis, o pai admite ao mesmo tempo a captação e a transfiguração do real por via da representação artificial: "[c]omo diz o compêndio de fotografia: a imagem apresenta um ordenamento inverso do real, mas captou-lhe os elementos essenciais" (OLIVEIRA, 2003, p. 25).

Ainda no plano do discurso das personagens e dos narradores, a presença do autor se revela em fragmentos que podem ser lidos como alusões ao próprio formato narrativo e a dificuldade por ele imposta aos leitores. Para citar apenas alguns exemplos, o adulto, desdobrado entre seu eu presente e a criança doutrora, em uma espécie de monólogo interior, diz ao menino ser "[d]ifícil distinguir o real por trás da encenação" (OLIVEIRA, 2003, p. 21), como a reconhecer que a "realidade", tal como concebida no mundo representado, é insoluvelmente ambígua e multifacetada. Também a mãe, ao afirmar que "há na teia malhas soltas para os dedos calosos" (OLIVEIRA, 2003, p. 109), alude, como a encarnar a voz do autor, não apenas à "teia das heranças" da família, mas também, indiretamente, aos fatos de não haver no romance uma única interpretação possível e de existirem sempre leitores dispostos a defrontar-se com a sua tessitura difícil. Função análoga desempenham as falas dispostas entre parênteses explicações, reiterações, opiniões -, as quais, embora pertencentes aos narradores e personagens (em sua maioria, ao homem), também contribuem para sugerir a presença do autor, dando a conhecer uma apreciação da matéria narrada e da lógica subjacente à ficção, como em "[n]ão te iludas [diz o homem ao menino, sobre a maquete construída pelo homem]. Apenas mudamos de enigmas. Embora eu duvide, porque (no fundo) há só um" (OLIVEIRA, 2003, p. 89, grifo nosso); "inserindo-se numa experiência nova (signos doutra lógica e doutra realidade), a ideia insinua que estou a viver por conta própria e a sonhar por conta de alguém" (OLIVEIRA, 2003, p. 98, grifo nosso). A alusão a um único enigma e à operacionalização de signos doutra lógica e doutra realidade vem desnudar, metalinguisticamente, a própria lógica ficcional - seu caráter enigmático, isto é, o texto como enigma maior, duplicado em enigmas menores, como a maquete, e a criação dum mundo imaginário e autônomo sobre as bases de um mundo real.

É, porém, na "Nota Final" de Finisterra que a presença do autor mais se revela. A voz enunciadora da "Nota" alude, entre outros aspectos, a "obsessões pessoais e sociais idênticas" do escritor, assegurando que a recuperação das mesmas obsessões em diferentes obras "[n]ão lhe parece grave, dada a frequência com que sucede aos romancistas repetirem o essencial (para eles) em vários enredos". "Grave seria", para tal voz, "não as ter aprofundado um pouco" (OLIVEIRA, 2003, p. 41, grifo nosso). Situada em uma fronteira tênue entre texto e paratexto, a "Nota" participa ao leitor a qualidade intencional da obra - não recorrendo ao que "tinha em mente" o autor ao concebê-la, tampouco justificando seus atributos com base em informações biográficas, mas sugerindo suas relações de continuidade e ruptura com a obra de Carlos de Oliveira poeta e prosador a partir das ideias mobilizadas em sua composição.

Afirma Rosa Maria Martelo (2000), com efeito, que $o$ essencial de que fala a "Nota" não reside senão em três princípios estruturantes extensíveis a toda a poesia e a ficção do autor: as noções de carência, transformação e precariedade. Explica ela que

\footnotetext{
[a] primeira corresponde a uma opção no jogo das contradições sociais e exprime a solidariedade com os desapossados de si e do mundo; a segunda activa um princípio geral do pensamento dialéctico com o qual se articula uma visão da História subordinada ao grande discurso clássico da emancipação, especificamente ao materialismo histórico; a terceira perspectiva subjectivamente os dois anteriores e introduz a dimensão individual, as obsessões pessoais do escritor (MARTELO, 2000, p. 253).
} 
A "solidariedade com os desapossados de si e do mundo" fora, como se sabe, a tônica do neorrealismo português, cujos desenvolvimentos se deram entre o fim da década de 1930 e o fim da década de 1950. Ainda que, sob o jugo salazarista, Portugal nesse tempo se encontrasse, em muitos sentidos, isolado do mundo europeu, influíram particularmente sobre a consciência dos escritores desse tempo os traumatismos sociais, econômicos e morais decorrentes da Primeira Guerra, agudizados pela crise econômica de 1929 e pela eclosão da Segunda Guerra. Partilhando das mesmas preocupações de um Alves Redol, de um Manuel da Fonseca e de um Mário Dionísio, Carlos de Oliveira fez de seus mundos de ficção palcos onde se encenam profundos conflitos de classe e onde se desdobram a ascensão e a ruína de sistemas econômicos de produção baseados na exploração agrária, ameaçados pela indústria. Em Finisterra, não diferentemente, é nuclear a problemática econômica, correspondendo as grandes tensões que movimentam a intriga, como observa Maria Lúcia Lepecki (1979), a "manifestações afectivas de realidades económico-sociais”. Isto é, “[m]otivadas por questões levantadas em torno do estatuto e da situação desta propriedade privada, surgem tensões, a chamarem-se endógenas, entre o pai e o filho, o pai e a memória do avô, marido e mulher, mãe e filho" (LEPECKI, 1979, p. 209). Sendo extremas todas essas tensões, é mais extrema ainda a provocada "pelo medo da mudança (de ricos senhores em lavradores hipotecados) e pela sensação profunda de instabilidade" (LEPECKI, 1979, p. 209). Os habitantes de Finisterra, como os das outras casas de Carlos de Oliveira, lutam contra condições naturais adversas, com exteriores que aceleram o processo de decadência, assim como procuram, em vão, resistir aos tormentos de uma psicologia, ou antes, de uma casa interior, igualmente em crise. Em Finisterra, como também na poesia e na prosa romanesca do autor, há a projeção de um porvir em que os explorados finalmente logram a emancipação - em Carlos de Oliveira, vemos essa projeção materializada, por exemplo, na casa incendiada de Casa na duna, na esperança cega de Raimundo da Mula de Pequenos burgueses, na semente plantada pelo corpo morto de Clara de Uma abelha na chuva, nos peregrinos autonomizados e na planta carnívora que consome a casa de Finisterra. Embora esse ideal figure apenas como projeção, priorizando-se a representação de conflitos interclasses, sua presença é bastante para demarcar a solidariedade da obra com os grupos sociais explorados.

Quanto à "dimensão individual" de que fala Rosa Maria Martelo, isto é, as obsessões pessoais do escritor, elas correspondem, antes de mais, à construção do imaginário da Gândara e a motivos como o desenho infantil, a febre, a solidão, o grão de areia, o halo de luz, o papel da memória, a obsessão da infância e a instabilidade do solo, que atravessam tanto a produção poética quanto a produção narrativa de Carlos de Oliveira. O próprio autor, no ensaio "Micropaisagem", da coletânea "O aprendiz de feiticeiro", afirma que

\begin{abstract}
Desses elementos se sustenta bastante toda a escrita de que sou capaz, umas vezes explícitos, muitas outras apenas sugeridos na brevidade dos textos. E disse sem querer uma palavra essencial para mim. Brevidade. Casas construídas com adobos que duram sensivelmente o que dura uma vida humana. Pinhais que os camponeses plantam na infância para derrubar pouco antes de morrer. A própria terra é passageira: dunas modeladas, desfeitas pelo vento. Que literatura poderia nascer daqui que não fosse marcada por esta opressiva brevidade, por este tom precário, demais a mais tão coincidentes com os sentimentos do autor? (OLIVEIRA, 1979, p. 207).
\end{abstract}

Por outro lado, apesar da diversidade de pontos de contato a nível diegético e ideológico, são radicalmente diversas as necessidades de Finisterra em relação aos demais romances do autor, desde logo porque, como já aludimos, o próprio romance - ou, antes, a perspectiva do autor que se deixa deduzir por detrás do discurso dos narradores e das personagens - advoga a permanência dessas analogias apenas no nível da sugestão. Finisterra faz menos do que contar uma história do que encenar, na própria experiência das personagens, a impossibilidade do conhecimento direto de um certo mundo. 
O que há, a nosso ver, de mais particular no romance derradeiro de Carlos de Oliveira é a relação entre a paisagem interna, a casa, e a paisagem externa, a terra enquadrada pela janela. Sem deixar de contar uma história, a história da decadência de uma certa família, o romance nos dá a conhecer a relação dessa família com um exterior simultaneamente ameaçador e tentador. É pela perspectivação da paisagem externa a partir da casa que o romance produz a reflexão sobre si próprio, o desdobramento para o seu próprio interior e a tematização metafórica daquilo que no discurso teórico é conceptualização (GUERREIRO, 1980, p. 80) - a ideia de que o real, tão obsessivamente perseguido por parte da ficção, é, em última instância, inatingível.

Pai, mãe, menino, homem criam versões de um espaço que se constitui fundamentalmente por elementos heterogêneos como areia, gramíneas, dunas, lagoa, céu e mar. Imprimem eles a sua percepção particular desses elementos na descrição verbal, no desenho, na pirogravura e na fotografia. No desenho feito pela criança, a paisagem é deliberadamente transfigurada. O menino a reproduz "de cór" entre as flores selvagens do jardim familiar, assim que um revérbero de luz fende as nuvens. Por um trabalho de elaboração, não apenas "cria os seres primordiais, mistura verão e inverno, atenua a cegueira incidindo sobre a sílica [...], aumenta os grãos de areia" (OLIVEIRA, 2003, p. 9), como também povoa a paisagem desolada:

surgem recortados a negro (exceto as cabeças que são laivos de fogo) os primeiros homens, cavalos, bois, carneiros, caminhando a custo entre grãos de areia grandes como penedias. Procuram matar a sede na lagoa pouco maior que uma gota de chuva. Ao alto, sobre as dunas distantes, com as asas rente às margens do papel, pairam aves brancas, esperando com certeza a sua vez de beber (OLIVEIRA, 2003, p. 13).

No almofadão de carneira pirogravada pela mãe, a paisagem é sugerida em uma "gravura abstracta" que, entretanto, "repete com rigor o traço das dunas, as margens da lagoa, a rede confusa das gramíneas, equilibrando geometricamente superfícies, volumes, relações de espaço: a arquitetura real (?) da paisagem” (OLIVEIRA, 2003, p. 12).

$\mathrm{Na}$ fotografia feita pelo pai, reproduz-se a mesma paisagem, alterando-se, porém, "a cor real":

o tempo destingiu a imagem: os contrastes são pouco visíveis, desaparecem as três zonas distintas, dissolvem numa única mancha castanha (quase sépia) à medida que os anos (e a réstia de sol batendo na parede pelo fim da tarde) devoram linha a linha a nitidez dos contornos. Reconhece-se ainda a paisagem, mas há sobre as coisas o resíduo dum luar lento que se esconde (como nas sanguíneas oitocentistas) para lá das últimas dunas (OLIVEIRA, 2003, p. 12).

Diante de Finisterra, tem-se a impressão de que, enquanto a linguagem persegue, com seu rigor descritivo, uma imagem objetiva da paisagem familiar, o próprio motor do percurso ficcional - a memória, a fantasia, os afetos, a natureza do material utilizado para representação - põe-no em xeque, trazendo à tona a parcialidade implicada em todas as visões que compõem esse mundo. No nível da história, essa dinâmica é duplicada na obsessão das personagens em fixar o mundo visto da janela e no seu resultado sempre deceptivo - tudo se passa como se, ao dramatizar a representação, o romance descobrisse em si próprio "o malogro de seu projeto: representar não é fixar, mas irradiar sentidos" (SEIXO, 1986, p. 73). Quer dizer, a parcialidade em que se inscreve o mundo ficcional convive com a "intencionalidade objetal e microscópica" que atravessa o comportamento dos habitantes da casa. Ao fazer concorrer essas duas tendências, a objetividade pretendida pelas personagens e a parcialidade de tudo desde logo desvendada pelo leitor, o romance põe em causa a própria possibilidade da ficção em suas vertentes naturalistas. Isto é, as descrições longas e pormenorizadas, assim como as reproduções da paisagem externa em desenho, fotografia e pirogravura, pretendendo-se fieis aos objetos representados, não são bastantes para impedir que todo o mundo se radique na percepção das figuras que o habitam - não só porque quem narra, nesse relato, é "um homem que 
vê, que sente, que imagina, um homem situado no espaço e no tempo, condicionado por suas paixões" (ROBBE-GRILLET, 1969, p. 93), mas também porque

[a] preocupação com a precisão, que às vezes está próxima do delírio [...] não consegue impedir o mundo de ser algo móvel até em seus aspectos os mais materiais, e mesmo no seio de sua aparente imobilidade. Aqui não se trata mais do tempo que corre, uma vez que paradoxalmente os gestos só são dados como fixados naquele momento. É a própria matéria que é ao mesmo tempo sólida e instável, ao mesmo tempo presente e sonhada, estranha ao homem e incessantemente inventando-se a si mesma na mente do homem. Todo o interesse das páginas descritivas - isto é, o lugar do homem nessas páginas - não está mais na coisa descrita, mas no próprio movimento da descrição (ROBBEGRILLET, 1969, p. 99).

Em Finisterra, como quer Luís Mourão (1996), "[e]stamos não só nos limites de um território textual, como nos limites da ideia de literatura que genericamente identificava esse mesmo território textual" (MOURÃO, 1996, p. 288). Não é por acaso que a mãe, como se deixasse falar pela sua a voz do autor, assume ter abandonado antigas pretensões ("desisti de perseguir a realidade, ou melhor, cansei-me" (OLIVEIRA, 2003, p. 77). Assim, se, como quer Martelo, "Finisterra não esquece o seu passado" (MARTELO, 2000, p. 259), esse passado ocupa nele um segundo plano; o primeiro é concedido ao próprio processo ficcional, tornado um amplo campo de exploração de suas próprias possibilidades representativas. Tal parece ser o "aprofundamento" de que nos fala a "Nota Final".

Mas se tais pontos de continuidade e ruptura admitimos, é porque colocamos em ação as potencialidades semânticas da narrativa, porque articulamos estratégias narrativas com informações relativas ao contexto de produção da obra, a diretrizes ideológicas mobilizadas em sua feitura, a outros textos do mesmo autor e a convenções de representação por ela postas em causa; é porque admitimos que
Finisterra participa de uma vida literária e social cujas condições podem ser recuperadas sem que sua especificidade discursiva seja descuidada; é, em suma, porque consideramos a "intenção do autor" uma dimensão do significado do texto.

Como Paul Ricoeur (1976), reconhecemos que a teoria literária nos colocou diante de um embate entre duas posições radicais: "[p]or um lado, teríamos o que W.K. Wimsatt chama a falácia intencional, que sustenta a intenção do autor como critério para qualquer interpretação válida do texto", por outro, teríamos o que Ricoeur chama "a falácia do texto absoluto”, isto é, “a hipostasiação do texto como uma entidade sem autor" (RICOEUR, 1976, p. 42). Ora, "[s]e a falácia intencional passa por alto a autonomia semântica do texto, a falácia contrária esquece que num texto permanece um discurso dito por alguém e mais alguém acerca de alguma coisa", sendo "impossível eliminar de todo esta característica principal do discurso, sem reduzir os textos a objetos naturais, isto é, a coisas que não são feitas pelo homem, mas que, como calhaus, se encontram na areia”. Entretanto, “[o] significado autoral torna-se justamente uma dimensão do texto na medida em que o autor já não está disponível para ser interrogado. Quando o texto já não responde, então tem um autor, e já não um locutor" (RICOEUR, 1976, p. 42).

$\mathrm{O}$ assassinato do autor, desdobrado ao longo do século XX e consolidado com o golpe final do chamado pós-estruturalismo, foi decerto condição necessária ao desenvolvimento da teoria literária. Se hoje conceitos como "forma", "sentido", "interpretação", "história”, “discurso", "narrador" são categorias fundamentais dos estudos narrativos, isso se deve, em larga medida, à negação da psicologia e da biografia do autor como critério interpretativo.

Porém, em textos como Finisterra, cuja consciência aguda da forma e dos limites de sua própria natureza ficcional tende a combinar-se com a rasura da soberania do narrador, com a variação e a multiplicidade de perspectivas, atribuir às instâncias narrativas toda a responsabilidade pela transmissão da mensagem do texto, como se faz em um paradigma narratológico tradicional, não é suficiente para 
dar conta dum excedente de significado obtido do confronto entre as diferentes perspectivas, da comparação entre diferentes estratégias de configuração das personagens, dos modos de representação do tempo e do espaço, das ironias e das ambiguidades propositalmente instauradas. Por presença do autor em Finisterra, compreendemos, em suma, a manifestação de um comprometimento moral com o núcleo peregrino e com o ponto de vista solidário e igualitário que esse núcleo representa, assim como a postura contestatória assumida diante da possibilidade de representar-se objetivamente o mundo - o que fica evidente se considerarmos, por um lado, as estratégias de ficcionalização que participam da relação entre os níveis narrativos, o contraste entre diferentes concepções em torno da atividade mimética, e por outro, os pressupostos axiológicos que se deduzem da articulação com outros textos do autor e com o contexto de produção. Ora, admitida a função do leitor de interpretar as potencialidades semânticas projetadas discursivamente, de cotejar as diferentes visões do mundo encenadas nas obras a partir da sua própria bagagem cultural e ideológica, abre-se caminho ao renascimento do autor enquanto critério interpretativo válido.

\section{Referências}

BOOTH, Wayne C. A retórica da ficção. Lisboa: Editora Arcádia, 1980.

ECO, Umberto. Obra aberta: forma e indeterminação nas poéticas contemporâneas. São Paulo: Perspectiva, 2015.

GENETTE, Gérard. Nouveau discours du récit. Paris: Seuil, 1983. https://doi.org/10.2307/1772332

GUERREIRO, António. A textualização do real (a partir de Finisterra de Carlos de Oliveira), Colóquio/Letras, Lisboa, v. 1, n. 104/105, p. 79-84, jul. 1988.

JANNIDIS, Fotis. "Author". In: HERMAN, David; JAHN, Manfred; RYAN, Marie-Laure (org.). Routledge Encyclopedia of Narrative Theory. London-New-York: Routledge, 2005. p. 85-86. https://doi.org/10.1177/09639470070100050603

KINDT, Tom; MÜLLER, Hans Harald. The implied author. Concept and controversy. Berlim: Gruyter, 2006. https:// doi.org/10.1515/arbi.2008.084
LANDA, José Ángel García. Perspectiva. In: LANDA, José Ángel García. Acción, relato, discurso: estructura de la ficción narrativa. Salamanca: Ediciones Universidad Salamanca, 1998. p. 184-192.

LEPECKI, Maria Lúcia. "Carlos de Oliveira: entre narrativa e poesia”. In. LEPECKI, Maria Lúcia. Meridianos do texto. Lisboa: Assírio e Alvim, 1979. p. 203-213.

MARTELO, Rosa Maria. Casas destruídas. A revisitação de Casa na duna em Finisterra de Carlos de Oliveira. Línguas e Literaturas: Revista da Faculdade de Letras, Porto, v. 18, p. 251-260, 2000. https://doi.org/10.17771/pucrio.acad.16081

MOURÃO, Luís. O Agrimensor da sombra. In: MOURÃO, Luís. Um romance de impoder. A paragem da história na ficção portuguesa contemporânea. Braga-Coimbra: Angelus Novus, 1996. p. 267-302.

OLIVEIRA, Carlos de. Finisterra. Paisagem e Povoamento. Lisboa: Assírio e Alvim, 2003.

RICOEUR, Paul. Teoria da interpretação. O discurso e o excesso de significação. Lisboa: Edições 70, 1976.

ROBBE-GRILLET, Alain. Por um novo romance. São Paulo: Documentos, 1969.

SEIXO, Maria Alzira. Escrever a terra - sobre a inscrição do espaço no romance português contemporâneo. In: SEIXO, Maria Alzira. A palavra do romance: ensaios de genologia e análise. Lisboa: Livros Horizonte, 1986. p. 69-81. https://doi. org $/ 10.3726 / 978-3-0.352-6.554-5 / 10$

Recebido em: 22/7/2019

Aprovado em: 3/9/2019

\#34948

SEÇÃO: ENSAIOS

\section{Giseli Seeger}

Universidade Federal de Santa Maria (UFSM), Santa Maria, RS, Brasil

Orcid: http://orcid.org/0000-0003-2866-7053

E-mail: giseliseeger@gmail.com

Endereço de correspondência: Rua Visconde de Pelotas, 1722, apto. 41, Bairro Nossa Senhora de Fátima, Santa Maria - RS

Cep. 97015140 